\title{
Educando Corpos, produzindo Diferenças: um debate sobre gênero nas práticas pedagógicas ${ }^{1}$
}

Alfrâncio Ferreira Dias ${ }^{2}$

\section{Resumo:}

Neste artigo pretende-se refletir acerca das práticas escolares contemporâneas,e busca identificar como a escola educa corpos masculinos e femininos em suas práticas pedagógicas. Parte-se da ideia de como, no processo educativo, o indivíduo é educado para o controle da sexualidade, do desejo e para desenvolverpapéis sociais ligadosà masculinidade e à feminilidade. Discute-se o papel dos agentes escolares na construção e reproduçãode um ideal de masculinidade e feminilidade, mostrando como as diferenças de gênero se transformam em desigualdades. Conflui-se na tentativa de mostrar a necessidade de incluir o princípio da coeducação para ampliação das relações de gênero nas práticas educativas, bem como as desigualdades no campo da educação. Palavras-chave: Corpo. Desigualdades. Gênero. Práticas Educativas.

\footnotetext{
${ }^{1}$ Este artigo é fruto de análises desenvolvidas a partir do Projeto de Pesquisa "Introduzindo a perspectiva de gênero na formação docente para uma educação não discriminadora" vinculado ao Programa de Pós-Graduação em Educação da Universidade Federal de Sergipe, bem como do Projeto de Extensão universitária "Formação de professores para uma educação não discriminadora” com financiamento interno (Edital PIBIX 2014).

${ }^{2}$ Doutor em Sociologia. Professor do Programa de Pós-graduação em Educação e do Departamento de Educação na Universidade Federal de Sergipe, Campus Itabaiana. E-mail: diasalfrancio@hotmail.com.
} 


\title{
Educating Bodies, Producing Differences: a debate about gender in pedagogical practice
}

\begin{abstract}
:
This article aims to reflect on the contemporary school practices, and seeks to identify how the school educates male and female bodies in their pedagogical practices. It starts with the idea of how, in the educational process, the individual is educated for the control of sexuality, desire, and to develop social roles related to masculinity and femininity. It discusses the role of school agents on the construction and reproduction of an ideal of masculinity and femininity, showing how gender differences are transformed into inequalities. It concludes in an attempt to show the need to include the principle of coeducation for expansion of gender relations in educational practices, as well as inequalities in education field.
\end{abstract}

Keywords: Body. Inequalities. Gender. Educational Practices.

\section{Introdução}

A escola como um espaço de sociabilidade é pensado aqui considerando três aspectos: como fonte de produção da realidade, como elemento de escolarização do corpo e como elemento de interações sociais que repercutem sobre seus conhecimentos, as identificações e experiências dos agentes. Parte-se das relações que se estabelecem entre docente/aluno, docente/meio, docente/sociedade para entender os sentidos do aprender e do ensinar dos/as docentes sobre o disciplinamento dos corpos, ou, até mesmo, a negação/anulação dos corpos nas práticas pedagógicas.

As representações dos corpos masculinos e femininos são questionadas dentro e fora das instituições escolares, com base nas 
questões coexistentes nas práticas sociais que influenciaram e influenciam a forma pela qual homens e mulheres desenvolvem a pedagogia da sexualidade. Percebe-se que essa prática desenvolve-se através dos tempos, e propõe,de forma discreta e contínua, a perpetuação do silenciamento do corpo, do desejo,e do erotismo na prática pedagógica. Assim, homens e mulherestreinados para não sentir e falar sobre desejo - tentamo desligamento ou separação do corpo e mente para desintegrar seus pensamentos, suas emoções e suas sexualidades do processo pedagógico. 0 fruto desse processo é a ideia de que a escola educa os corpos dos seus agentes, em todas as suas especificidades, a partir das formas pelas quais ensina, avalia, pune e define comportamentos masculinos e femininos.

As diversas práticas escolares tendem a reproduzir a ideia do corpo como um "lugar" sagrado e íntimo, a fim de desassociar o desejo e o prazer das relações escolares. É bastante comum, entre professores e professoras, a dificuldade de lidar ou falar sobre o corpo; quando são confrontados com determinados assuntos, raramente argumentam quanto às formas que lidam com as representações das masculinidades e feminilidades em suas salas de aulas. Talvez suas trajetórias familiares, escolares e sociais tenham lhes ensinado a anular a representação dos seus corpos, por isso reproduzem a necessidade de avaliar, categorizar e educar os corpos de meninos e meninas para a anulação da sexualidade, com o pressuposto de que a sala de aula não é um lugar para a representação do desejo, mas sim, de negar o corpo.

Assim, cabe questionar qual o lugar do corpo nas práticas pedagógicas das escolas? Quais as principais atitudes e atividades das escolas para não reproduzirem as diferenças e desigualdades de gênero em suas práticas educativas? Ou até mesmo, como as escolas estão educando meninos e meninas? Ao tentar responder essas indagações iniciais, pretendo refletir acerca de como as práticas escolares contemporâneas estão a educar os corpos de meninos e meninas para produzirem as diferenças, 
na tentativa de mostrar a necessidade de incluir o princípio da coeducação para ampliação das relações de gênero nas práticas educativas, bem como as desigualdades no campo da educação.

\section{Como as escolas educam corpos nas práticas pedagógicas?}

Compreendo que homens e mulheres participam de processos de socialização no decorrer de suas trajetórias familiar, escolar e social, de forma ativa/passiva, num processo de influenciar/ ser influenciado um ao outro, reproduzindo um discurso social e cultural. Em outras palavras, a representação das masculinidades e feminilidades no campo da educação pode interferir nos sentidos e significados atribuídos ao corpo, ao desejo e ao controle da sexualidade.

Percebo a cultura como um conjunto de significados/significantes o qual, através das tradições, se desvia para uma nova forma de situar-se, produzir-se, no sentido mais amplo, num processo de metamorfose em que novos conceitos, compreensões e caminhos permitem o surgimento de novos sujeitos. Admito que esse processo de mudança cultural, especificamente de papéis sociais, esteve por muito tempo adormecido nas instituições de ensino, a partir das reflexões quanto ao caminho que homens e mulheres percorreram na sociedade. Religião, tradições e costumes sociais pautaram, eainda estão a pautar, os modos de vida de homens e mulheres, direcionando para uma "doutrinação" dos corpos, na qual o principal objetivo seria a negação do desejo e o disciplinamento da masculinidade e feminilidade, tendo a escola como umas das principais ferramentas de catequização.

O antropólogo francês David Le Breton (2003) vem há muito tempo se dedicando ao estudo do corpo. Com uma leitura singular, Le Breton descreve as principais fases epistemológicas e discursivas do corpo, tornando-se uma referência para aqueles/ as que se dedicam a estudar um pouco mais acerca da perspec- 
tiva do corpo como um campo de análise científico. Especificamente, em Adeus ou corpo (2003), o autor descreve as principais formas de santificar o corpo para a sua anulação e dissociação do prazer, do desejo, da sexualidade, no decorrer da história 3 . Assim, em sua análise, o corpo é "colocado como um alter ego consagrado ao rancor dos cientistas, subtraído do homem que encarna à maneira de um objeto, esvaziado de seu caráter simbólico, o corpo também é esvaziado de qualquer valor" (LE BRETON, 2003, p. 15). 0 mesmo poder simbólico é desempenhado pelas escolas, no que se refere à escolarização dos corpos, visto que em suas práticas educativas, os meninos e meninas, homens e mulheres são ensinados a desenvolver a mente, a cognição, a aprendizagem, de forma a desvincular o corpo, seus desejos e sexualidades desse processo. Em síntese, anula-se o corpo nas salas de aula, numa perspectiva de separação entre mente e corpo, ou seja, corpos sem desejos, sem erotismo, sem sexo.

Na sala de aula, entram corpos que não têm desejo, que não pensam em sexo ou que são, especialmente, dessexualizados para adentrar esse recinto, como se corpo e mente existissem isoladamente um do outro ou como se os significados, constitutivos do que somos, aprendemos e sabemos, existissem separadamente de nossos desejos (LOPES, 2010, p. 126).

Por muito tempo, foi esse o argumento desenvolvido nas escolas. Ensinados a desprezar as representações do corpo, meninos e meninas foram disciplinados de todas as formas nas práticas educativas a se distanciarem do desejo, a representarem um corpo sem sexo no interior das salas de aulas. Na verdade, percebe-se que a escola, frequentemente, desenvolve a perspectiva

\footnotetext{
${ }^{3}$ Esse aspecto é desenvolvido por Pacheco (2012, p. 110), no qual a "sexualidade expressaria a própria forca maior da repressão do sexo traduzida em manuais, textos científicos de como conter ou analisar os corpos. E a era dos discursos médicos e psicanalíticos sobre os corpos e da educação como instrumento para entender e controlar o comportamento sexual das crianças, das mulheres e dos homossexuais".
} 
social da sexualidade comointimamente ligada puramente ao espaço privado, e que tais discursos celebram a ideia de que a escola só tem espaço para desenvolver a aprendizagem, sendo que esta não poderia ser dificultadaatravés das representações dos desejos, dos corpos e sexualidades de meninos e meninas. É esse um dos principais argumentos de Louro (2010b), a qualparte da premissa de que quando a escola educa os corpos de meninos e meninas, ela também produz uma sexualidade tida como "normal". Em seu texto Pedagogias da sexualidade (2010b, p. 18), a autora passa a representar como a escola educa e normatizaos corpos,por meio de reflexões de suas próprias vivências escolares, deixando claro que no processo educativo, a "escola também deixou marcas expressivas em meu corpo e me ensinou a usá-lo de uma determinada forma”. Percebe-se que as marcas e ensinamentos descritos por Louro narram o poder que a escola exerce sobre seus agentes, especificamente no que se refere às representações das masculinidades e feminilidades: meninos e meninas são treinados, avaliados, categorizados e punidos pela necessidade de anulação da sexualidade, bem como educados a desenvolver as habilidades e comportamentos masculinos e femininos.

No processo educativo as pessoassão ensinadas a controlar a sexualidade,o desejo e a desenvolverpapéis sociais ligadosà masculinidade e à feminilidade, daí a tendênciaéque se reproduzamessas práticas simbólicas de controle, quando os professores desenvolvem suasaulas a partir de suas identificações sociais, em alguns casos, como se docentes e alunos não tivessem corpos, a fim de trabalhar apenas e puramente com a mente. Nesse contexto, as ideias de Bell Hooks (2010, p. 115) são relevantes para essa discussão, na medida em que "chamar atenção para o corpo é trair o legado de repressão e de negação que nos tem sido passado por nossos antecessores na profissão docente, os quais têm sido, geralmente, brancos e homens". A autora alertapara as dificuldades de situar o papel do professor no processo de anulação do corpo, bem como falar sobre desejo e sexualida- 
de nas situações de ensino. 0 fato é que professores aprendem a silenciar o desejo no processo pedagógico e reproduzem esse comportamento constantemente emsalade aula.

Nesse diapasão, demonstro como isso acontece na prática, através da análise do trabalho de Cruz e França (2011) desenvolvido acerca da educação feminina no Colégio Sagrado Coração de Jesus, na cidade de Estância (SE), mediante asmemórias e trajetórias de alunas. As autoras mostram como uma instituição religiosadesenvolvia a perspectiva do antifeminismo e inculcava nas suas práticas a moralidade, dominada principalmentepor valores patriarcais.

O controle da sexualidade era um item explícito nas ações pedagógicas da Instituição, com ênfase no androcentrismo, haja vista que a "ordem masculina se inscreve também nos corpos através de injunções táticas, implícitas nas rotinas da divisão do trabalho ou dos rituais coletivos e privados" (CRUZ; FRANÇA, 2011, p. 122). Para as autoras, a ordem social era desenvolvida intensamente dentro da Instituição, ensinando uma postura específica para os corpos, atribuindo papéis distintospara a masculinidadee feminilidade, no qual o "contato físico sob qualquer aspecto entre mulheres e homens e mulheres e mulheres era reprovado ou criticado" (CRUZ; FRANÇA, 2011, p. 122). A doutrinação e policiamento dos corpos era uma das grandes características das escolas religiosas, exercendo influências sobre as mais variadas formas de negação do corpo, bem como influências na construção das personalidades dos alunos e alunas. Seguemos dos depoimentos recolhidos pelas pesquisadoras:

Havia muita malícia expressa pelas religiosas sobre os relacionamentos femininos, ou seja, elas tinham temor de relações "homossexuais" ou "muito próximas" entre meninas e meninas e entre as professoras. Os boatos sobre namoros de pessoas conhecidas e das alunas eram propagados aluno no colégio (sic). 
EDUCANDO CORPOS, PRODUZINDO DIFERENÇAS:

UM DEBATE SOBRE GÊNERO NAS PRÁTICAS PEDAGÓGICAS

No cotidiano do colégio, eram criados mistérios e proibições! Os meninos não podiam conversar com as meninas.

A disciplina no Colégio era igual ao regime militar.

A Irmã A......e Irmã C....... tinham o controle da vida das pessoas. Havia o controle das preferências, ela era tendenciosa e manipulava a vida das alunas preferidas. (CRUZ; FRANÇA, 2011, p. 124).

O que as falas das entrevistas demonstram é que a Instituição de Ensino desenvolvia o controle da sexualidade mediante a perspectiva cultural, por considerar como um ato proibido, reprimido e inerente ao espaço privado. 0 desejo e a sexualidade não poderiam ser discutidos nos espaços educativos e sociais, mas sim silenciados e anulados cotidianamente.

Segundo Bell Hooks (2010), nas práticas escolares, como no contexto familiar, as pessoas são treinados a anular as representações dos corpos e dos prazeres, obedecendo a uma ótica social que sexo e prazer só acontecem na esfera privada. A autora vai além da discussão que perpassa sobos olhares dos alunos e alunos, chegando ao próprio professorado, visto que a maioria dos professore e professoras, disciplinados em seus processos formativos, não se sentem a vontade para falar sobre sues desejos, com o pressuposto de que na sala de aula não tem lugar para essas discussões. Confirma-se então a ideia de Xavier Filha (2011, p. 83) que apesar de estes "discursos pedagógicos ocuparem a mente do sujeito que se tornou escolarizável, os processos escolares na prática tiveram como propósito controlar, vigiar, regrar, moldar os corpos de meninos e meninas" (XAVIER FILHA, 2011, 83).

Nesse sentido, a escola em suas práticas educativas está a educar meninos e meninas para a anulação do corpo, quando investe no distanciamento da mente e corpo, quando normatiza a formação de homens e mulheres, quando desenvolve uma linguagem que padroniza masculinidades e feminilidades, quando 
nas situações diárias despreza as experiências e inter-relações de alunos e alunas e professores e professoras. Acreditoque a socialização contribui para intensificar essas relações, por intermédio das identificações sociais e sexuais, podendo surgir desse contextoas diferenças e desigualdades.

3 Como diferenças de gênero se transformam em desigualdades?

A adoção do conceito de gênero no âmbito dos estudos de mulheres e feministas tornou o gênero como campo científico. 0 conceito de gênero é compreendido como um divisor de águas para outra fase distinta da primeira onda do feminismo, e anunciador- de certa forma- da valorização significativa do diferencialismo, da afirmação política das diferenças, dos processos identitários e de igualdades; ou seja, o conceito chama a atenção para a diversidade ou as diferenças dentro da diferença.

Nessa linha de reflexão, defendo o gênero como uma categoria de análise histórico-cultural (LAURETIS, 1994), estabelecida pela experiência (THOMPSON, 1981; SCOTT, 1991). Segundo Lauretis (1994, p. 212), a "construção cultural do sexo em gênero e a assimetria que caracteriza todos os sistemas de gênero através das diferentes culturas (embora cada qual de seu modo) são entendidas como sendo sistematicamente ligadas à organização da desigualdade social".

Joan Scott também contribui para a fundamentação dessa perspectiva, visto que considera o gênero como "um elemento constitutivo das relações sociais fundadas sobre as diferenças percebidas entre os sexos" (SCOTT, 1995, p. 42). Assim, o gênero é visto como uma categoria explicativa para a análise histórico-cultural, pelo fato de que sua elaboração situa-se no conjunto das relações sociais, nas construções dessas relações e nos processos culturais vivenciados pela sociedade. Desse modo, as identificações de homens e mulheres são um produto das rela- 
ções sociais. Acredito que o gênero se estabelece pelas "experiências", pois é nos momentos cotidianos que as pessoas têm a tendência de expressar sua cultura. Thompson (1981), em 0 termo ausente, aborda a questão da "experiência social" para mostrar esse processo de construção do sujeito, fazendo uma crítica à teoria marxista, que pouco discutiu o aspecto cultural; ou seja, "o ausente" seria a cultura.

No contexto das pesquisas brasileiras, pode ser destacado o trabalho de Guacira Louro intitulado Gênero, sexualidade e educação (2010a), obra pós-estruturalista sobre a perspectiva do gênero como uma categoria de análise constituída a partir dos estudos do movimento feminista. Propõe um "pensamento plural" que ligue a concepção de gênero às representações sociais e não mais às argumentações biológicas. Segundo ela:

Pretende-se, dessa forma, recolocar o debate no campo do social, pois é nele que se constroem e se reproduzem as relações (desiguais) entre os sujeitos. As justificativas para as desigualdades precisariam ser buscadas não nas diferenças biológicas (se é que mesmo essas podem ser compreendidas fora de sua constituição social), mas sim nos arranjos sociais, na história, nas condições de acesso aos recursos da sociedade, nas formas de representação (LOURO, 2010a, p. 22).

A discussão relativa ao gênero, nesse caso, passa a ser pensada mediante acaracterização do que é masculino e do que é feminino na sociedade, das formas como os sujeitos compreendem e representam suas identificações nas práticas sociais, que assumem novos contornos no processo histórico. Assim, o conceito de gênero "passa a ser usado, então, como um forte apelo relacional - já que é no âmbito das relações sociais que se constroem os gêneros" (LOURO, 2010a, p. 22). Nesse aspecto, ao rever as características masculinas e femininas no contexto social, como propõe a autora, é preciso refletir acerca das relações sociais construídas por homens e mulheres, e não somente priorizar 
as mulheres em suas análises. 0 entendimento de "apelo relacional" está centrado na contextualização (no que se afirma ou supõe) sobre o gênero.

Nessa linha de pensamento, Cruz (2012) salienta que pensar a definição de gênero como uma construção social constitui um "princípio organizador" que influencia as experiências dos sujeitos, as formas de analisar e refletir quanto aos fenômenos, a fim de integrar (micro/macro, estrutura/sujeito) ao processo das relações sociais e, principalmente, na análise do desenvolvimento social.

Se, na sociedade, o conceito de gênero como construção social foi entendido através de um processo lento, influenciado fortemente pelos debates feministas; no contexto educacional, o sexo como um dos elementos para entender as novas conjunturas do trabalho docente é questão incorporada há pouco tempo. Em conformidade com essa linha de reflexão, Louro (2010a) ensina que algumas questões centrais das práticas educativas - como a produção das diferenças e das desigualdades sexuais de gênero, bem como as articulações com os outros marcadores sociais (raça, etnia, classe) - estão no bojo do debate acadêmico. A instituição escolar é um espaço privilegiado de socialização, nela recebe especial atenção o modo como os sujeitos - em relações sociais atravessadas por diferentes discursos, símbolos, representações e práticasvão construindo suas identificações, (re)construindo seus lugares sociais, suas disposições, suas formas de ser e estar no mundo.

A emergência dessa discussão em Louro (2010a) surge no texto A escolarização dos corpos e das mentes, no qual ela afirma que, quando a escola delimita "espaços", a construção de sentidos e significados são, por natureza, influenciados. 
EDUCANDO CORPOS, PRODUZINDO DIFERENÇAS:

UM DEBATE SOBRE GÊNERO NAS PRÁTICAS PEDAGÓGICAS

dos sujeitos implicadas na concepção, na organização e no fazer cotidiano escolar. 0 olhar precisa esquadrilhar as paredes, percorrer os corredores e salas, deter-se nas pessoas, nos seus gestos, suas roupas; é preciso perceber os sons, as falas, as sinetas e os silêncios; é necessário sentir os cheiros especiais; as cadências e os ritmos marcando os movimentos de adultos e crianças. Atentas/os aos pequenos indícios, veremos que até mesmo o tempo e o espaço da escola não são distribuídos nem usados - portanto, não são concebidos - do mesmo modo por todas as pessoas (LOURO, 2010b, p. 59).

Embora se perceba o trabalho de socialização desenvolvido no cotidiano das instituições escolares, este é constituído de um processo de "doutrinação" do espaço/tempo pensado para atender as características masculinas e femininas dos sujeitos que constituem o cotidiano escolar. Formas de comportamentos corporais, conteúdos disciplinares, currículos e linguagem nas práticas escolares permitem um controle do processo da escolarização, ditos como naturais. Contudo, "através de muitas instituições e práticas, essas concepções foram e são aprendidas e interiorizadas; tornam-se quase 'naturais' (ainda que sejam 'fatos culturais'). A escola é parte importante desse processo" 4 (LOURO, 2010b, p. 60).

Na verdade, para a autora, as relações de gênero constituem-se e reproduzem-se a partir das relações de poder. Assim, as desigualdades entre os homens e mulheres poderiam ser consideradas no âmbito das interações face a face; ou seja, no bojo das relações, ficando sem exame tanto as múltiplas formas que podem assumir as masculinidades e as feminilidades quanto as complexas redes de poder (através das instituições, dos discursos, dos códigos, das práticas e dos símbolos) que constituem hierarquias nas relações entre homens e mulheres.

\footnotetext{
4 “O processo de 'fabricação' dos sujeitos é continuado e geralmente muito sutil, quase imperceptível [...] a tarefa mais urgente talvez seja exatamente essa: desconfiar do que é tomado como 'natural'" (LOURO, 2010b, p. 63).
} 
A noção de dicotomia é muito interessante para este debate, visto que, dentro de um determinado contexto social, homens e mulheres são sujeitos ativos, com especificidades que podem desestabilizar a relação homem dominador/mulher dominada, ou o gênero forte dominando o fraco, a fim de entender quenessa relação binária de poderserão tecidas novas formas de domínio.

Para Bourdieu (1999), a divisão das coisas e atividades, de acordo com a oposição entre masculino e feminino, recebe sua necessidade objetiva de integração em um sistema de oposições homólogas (alto/ baixo, dentro/fora, frente/trás, direita/esquerda, direito/curvo, seco/úmido, duro/mole, picante/insípido, claro/escuro). Ao se tornarem semelhantes ao litígio, são bastante consistentes para manter-se no e através do interminável jogo de transferências e de metáforas, e bastante divergentes para conferir a cada um deles uma espécie de espessura semântica, mediante a sobredeterminação harmônicadas conotações e das correspondências. Um forte indício disso é a separação entre a esfera pública e a esfera privada, longamente criticada pelas feministas como um dos exemplos mais fortes das relações de poder.

Não há dúvida de que esse processo de separação entre o público e o privado tem como eixo central o corpo. 0 corpo masculino, mais forte, era considerado nato para o trabalho (produtor - esfera pública); já o corpo feminino, mais frágil, é/era associado ao aspecto natural da reprodução (reprodutora - esfera privada). 0 pensamento de Michel Foucault, em Vigiar e punir (1987) contribui com outros olhares para explicar as relações de poder entre os gêneros no campo da educação, através da análise da normatização da conduta de meninos e meninas, professores e professoras, bem como a produção dos saberes sobre sexualidade e os corpos nos múltiplos processos educativos. Na perspectiva de Foucault (1987), as instituições escolares podem, em suas práticas cotidianas, criar mecanismos de controle disciplinador do corpo, bem como outros mecanismos disciplinadores, como- 
formas de poder simbólico das instituições escolares. Embora já se perceba um distanciamento de alguns pesquisadores sobre a ideia do corpo como um espaço de poder, Michel Foucault salienta a sua importância no campo político.

0 corpo também está diretamente mergulhado num campo político; as relações de poder têm alcance imediato sobre ele; elas o investem, o marcam, o dirigem, o supliciam, sujeitam-no a trabalhos, obrigam-no a cerimônias, exigem-lhe sinais. Este investimento político do corpo está ligado, segundo relações complexas e recíprocas, à sua utilização econômica; é, numa boa proporção, como força de produção que o corpo é investido por relações de poder e de dominação; mas em compensação sua constituição como força de trabalho só é possível se ele está preso num sistema de sujeição (onde a necessidade é também um instrumento político cuidadosamente organizado, calculado e utilizado); o corpo só se torna força útil se é ao mesmo tempo corpo produtivo e corpo submisso. Essa sujeição não é obtida só pelos instrumentos da violência ou da ideologia; pode muito bem ser direta, física, usar a força contra a força, agir sobre elementos materiais sem, no entanto, ser violenta; pode ser calculada, organizada, tecnicamente pensada, pode ser sutil, não fazer uso de armas nem do terror, e no entanto continuar a ser de ordem física (FOUCAULT, 1987, p. 29).

A forma de ver o corpo do outro como útil justifica a dominação patriarcal da esfera privada, a partir do entendimento da produção (no caso das mulheres, o trabalho doméstico e sem remuneração), ${ }^{5}$ bem como do processo de submissão ao poder do homem dentro da família. As relações de poder têm um significado natural de ação dominadora, na medida em que "o poder

\footnotetext{
${ }^{5}$ Por muito tempo, a vida da maioria das mulheres se restringiu ao desenvolvimento de papéis privados, que demonstravam onde se localizavam, como estavam seus corpos dentro de suas casas, como eram seus gestos cotidianos, por vezes, repetitivos. Essa representação está exposta em A Confecção das mulheres (SOFFER et al., 2009), obra que mostra o processo de constituição de um lugar para as mulheres - o lar —, bem como suas funções.
} 
pode ser visto sob duas perspectivas: o poder como capacidade de agir sobre as coisas e o poder como capacidade de determinar o comportamento de outros" (PARO, 2010, p. 33). Dessa forma, a questão do poder colocou-se rapidamente, uma vez que tal elemento possui um caráter fundante na relação entre os sexos (PERROT, 2005). A relação foi declinada em todas as suas formas: poder, influência, força, decisão etc.. A distinção entre público e privado apresentou-se, ao longo do tempo, como categoria política, expressão e meio de uma vontade de decisão sexual dos papéis, das tarefas, dos espaços, produtora de um real e constante remodelar.

Mas, afinal, o que essa discussão tem a ver com as práticas educativas? Qual o propósito de trazer à tona a discussão de gênero para esse contexto? Entendo a escola como um microssistemada sociedadeque exerce influências sobre os agentes que se socializam nesse campo, e suas identificações sociais (construídas a partir das trajetórias familiares e sociais) tendem a sercolocadas em prática. Assim, quando os agentes escolares partem das diferenças biológicas entre homens e mulheres para construírem e reproduzirem um ideal de masculinidade e feminilidade para justificar a inferiorização, as desigualdades começam a surgir nas práticas escolares.

Para Carvalho, Andrade e Menezes (2009), as desigualdades começam a surgir quando, nos processos culturais, os agentes sociais lançam mão de características masculinas e femininas mediante o binarismo para fixar como homens e mulheres devem "ser", desprezando as diferenças individuais e a diversidade. Ditam-se, então, comportamentos, valores, modos de agir e pensar para homens e mulheres, criando um perfil ideal de masculinidade e feminilidade para educar meninos e meninas que refletirão nas suas trajetórias familiares, escolares e sociais. Para aqueles e aquelas que não se enquadram nesses estereótipos valorizados socialmente são "vítimas de discriminações e preconceito, a exemplo das pessoas homossexuais, bissexuais e 
transgêneros. Desse modo, diferenças têm sito transformadas em desigualdades" (CARVALHO; ANDRADE; MENEZES, 2009, p. 12). Nas práticas educativas, esses estereótipos também são valorizados e, em alguns casos essas diferenças se tornam desigualdades nas salas de aula, aos que não se adéquam a ela, tornando-a um lugar de preconceito e de pouco enfrentamento da diversidade.

Especificamente, quanto à valorização das masculinidades e feminilidades, relato uma experiência pessoal quando em visitaa instituições de ensino de educação infantil para desenvolver pesquisas na área da diversidade. Em uma dessas visitas,uma professora mostrou-me um aluno de cinco anos, e fez o seguinte comentário:"professor, não está vendo aquele menino ali com um jeitinho estranho de mulher. Acho que ele será viadinho! Mas, daqui para o final do ano letivo eu tiro esse jeitinho dele". Perplexo com o preconceito expresso no comentário, a questionei: “Comoasenhora sabe que ele será homossexual? Só por conta da representação de traços femininos?” A professora foi categórica: "Nas minhas aulas não tolero esse tipo de desvio, pois meninos têm que se tornarem homens e outra coisa". Este exemplo foi analisado em outro trabalho, mas ele é determinante para representar que nas salas de aula alguns professores e professoras não estão preparados e familiarizados com as diferenças, e desenvolvem suas aulaspor intermédio de um esquema binário do "ser homem" e "ser mulher", desprezando a perspectiva de que a masculinidade e a feminilidade são plurais e socialmente construídas, e não apenas como algo da natureza. 0 que confirma o argumento de Moreno (1999, p. 30), pois para a autora esses "modelos de comportamento atuam como organizadores inconscientes da ação, e é esta característica de inconsciência que os torna mais dificilmente modificáveis".

Seria preciso criar novas e múltiplas formas de lidar com a escolarização de meninos e meninas (CARVALHO, 2012), a fim de pensar para além da doutrinação ou anulação dos comportamentos masculinos e femininos nas práticas escolares. Um 
caminho interessante para a diminuição das descriminações e desigualdades nas salas de aula seria uma prática pedagógica a partir da perspectiva da coeducação.

\section{Por uma pedagogia da coeducação}

As representações de gênero relativas ao trabalho docente anunciam a existência de estereótipos ligados à masculinidade e à feminilidade reconhecidos, prioritariamente, pelas mulheres, consideradas as suas vivências no campo do trabalho, ao mesmo tempo em que se percebe nas narrativas que estas estão representando os processos de relações do "eu" com os "outros" (homens/mulheres, mulheres/mulheres e homens/homens), ou seja, da alteridade. No campo das interações sociais, a masculinidade e a feminilidade são ressignificadas num processo complexo, no qual as relações nas práticas educativas influenciam o significado atribuído às diferenças entre os sexos.

As representações sociais relativas a homens e mulheres docentes são pensadas em conformidade com o trabalho que realizam, num espaço de relações dinâmicas e ambíguas, que descrevem as narrativas, as imagens de gênero, os papéis de homens e mulheres, das masculinidades e feminilidades que configuram as práticas de socialização no interior da escola. Nesse sentido, as mudanças de consciência concernentes às relações de gênero são fundamentais para entender as identidades/alteridades dos/as agentes escolares, sendo necessárias novas formas de organização do trabalho a fim de ampliar os espaços de socialização da escola, uma vez que essas relações acabam por indissociar as identidades/subjetividades dos/as agentes escolares, em consonância com a atribuição de sentidos a prática educativa, ao aprender e ao ensinar, que suas identidades sociais se constroem.

A preocupação seria apenas como um caminho a ser percorrido por meninos e meninas nas escolas, visto que - como todo 
processo de socialização - a escola, em suas práticas, utiliza e reproduz algumas diferençasatravés das identificações de seus agentes. Entretanto, meninos e meninas não são mais receptores passivos dessa reprodução, pois a tentativaque a escola faz de anular, vigiar, escolarizar o corpo já está sendo questionada por muitos alunos e alunas nas salas de aulas. Segundo Auad (2006, p. 78) meninos e meninas no contexto escolar "reagem, seja ao recusar ou ao assumir, às aprendizagens sobre o feminino e o masculino, propostas implícita e explicitamente nos processos educacionais". Embora, de diferentes formas, as reações de meninos e meninas são o bastante para iniciar um processo de desestabilização das práticas educativas tradicionais, aquelas que definiamprincipalmentecomportamentos, gestos, coisas, como femininas e masculinas estão paulatinamente sendo recusadas no cotidiano escolar.Além da recusa, há o enfrentamento às práticas tradicionaismediante as representações de suas identificações.

Para Carvalho (2009), a formação dos professores e professoras e as práticas educativas estão mais sensíveis às questões de gênero, atualmente. Percebe-se a necessidade de refletir maisacerca da construção e desconstrução das representações dos significados das masculinidades e feminilidades no campo da educação, seja nas salas de aula como também nos cursos de formação de professores. Percebe-se que o caminho inicial para a democratização das práticas escolares está intimamente ligado ao processo educativo, neste sentido, "admite-se que a educação, os processos escolares e as ações docentes influenciam a equidade ou iniquidade de gênero e, inversamente, que o gênero impacta as experiências e os resultados educacionais" (CARVALHO, 2009, p. 31).

É importante compreender que as ações dos agentes escolares são determinantes e influenciam na transformação das práticas educativas, criando ambientes de tolerância às diversidades, bem como mudanças na própria organização escolar. Nesta 
perspectiva, como progredir para esse cenário futuro? A perspectiva que chamo de Pedagogia da Coeducação pode ser o pontapé inicial para a criação de práticas educativas mais significativas e plurais e menos desiguais.Utilizo as concepções de Daniela Auad sobre a prática da coeducação, por acreditar que a autora é uma das pesquisadoras brasileiras que mais desenvolveu a perspectiva da coeducação para a ampliação das formas de educar meninos e meninos, bem como o desenvolvimento de políticas públicas para a igualdade de gênero. Segundo ela a coeducação refere-se:

A um modo de gerenciar as relações de gênero na escola, de maneira a questionar e reconstruir as ideias sobre o feminino e sobre o masculino. Trata-se de uma política educacional, que prevê um conjunto de medidas e ações a serem implementadas nos sistemas de ensino, nas unidades escolares, nos afazeres das salas de aulas e nos jogos e nas brincadeiras dos pátios (AUAD, 2006, p. 79).

Acredita-se que a partir da reconstrução das masculinidades e feminilidades no campo da educação, novas formas de ver e agir nas práticas educativas poderá surgir e se constituir como ações permanentes. Mais que isso, novas formas de organização do trabalho pedagógico, para que as atividades didático-pedagógicas passem a alcançar a equidade entre meninos e meninas, nas ações diárias, nas aulas, nos jogos e brincadeiras. Para tanto, faz-se necessário o desenvolvimento formativo e político dos agentes escolares para que estes possam desenvolver "ações" e "mudanças", dentro do ambiente escolar e fora dele, para que as práticas coeducativas se desenvolvam, numa perspectiva macro/micro, objetiva/subjetiva, geral/particular.

Segundo Auad (2006, p. 81-84), para que isso aconteça é preciso que algumas transformações sejam realizadas para que, de fato, a igualdade de gênero se desenvolva nas escolas, tais como: mudançasna legislação; nos sistemas educativos; nas unidades escolares; nos currículos; nas interações entre professoras, pro- 
fessores, alunos e alunas; capacitação e formação profissional; paridade do professorado; livros didáticos que não reproduzam as desigualdades de gênero.

Mesmo que essas ações gerais não se desenvolvam rapidamente em todas as escolas, ou seja, como uma política pública, professores e professoras podem e devem assumir e desenvolver medidas da perspectiva da Pedagogia da Coeducação em suas práticas diárias, pois a coeducação "figura não apenas como política pública, mas também como oportunidade de encontro, debate e celebração entre muitos e diferentes sujeitos que atuam e constroem o conhecimento, a educação e os movimentos sociais." (AUAD, 2006, p. 87).

\section{Conclusão}

Diante das reflexões e discussões abordadas em um tema tão dinâmico e complexo, é impossível ter a pretensão de ter estudado e compreendido todas as perspectivas dessa temática. Entretanto, ousei refletir acerca das representações de gênero no campo da educação, destacando o papel da escola na educação dos corpos de meninos e meninas, na diminuição das desigualdades e a produção de práticas mais igualitária, não apenas para atender a produção desse artigo, mas, principalmente, discutir acerca das relações de gênero na docência, campo de atuação profissional do pesquisador. 


\section{Referências bibliográficas}

AUAD, Daniela. Educar meninas e meninos: relações de gênero na escola. São Paulo: Contexto, 2006.

BOURDIEU, Pierre. A dominação masculina. Rio de Janeiro: Bertand Brasil, 1999.

CARVALHO, Marília Pinto de. Diferenças e desigualdades na escola. Campinas/SP: Papirus, 2012.

CARVALHO, M. E. P. de; ANDRADE, F. C. B. de; MENEZES, C. S. de. Equidade de gênero e diversidade sexual na escola: por uma prática pedagógica inclusiva. João Pessoa: Ed. Universitária/UFPB, 2009.

CRUZ, Maria Helena Santana; FRANÇA, Vera Lúcia Alves. Memória e trajetórias de alunas do Colégio Sagrado Coração de Jesus em Estância - Sergipe (1950-1970). São Cristóvão: Editora UFS, 2011.

. Refletindo sobre a diversidade de gênero no campo da Educação.

Revista Saberes em Perspectivas, v. 2, n. 2, p. 13-32, jan./abr. 2012.

FOUCAULT, Michel. Vigiar e punir: nascimento da punição. Petrópolis: Vozes, 1987.

HOOKS, Bell. Eros, erotismo e o processo pedagógico. In: LOURO, Guacira Lopes. 0 corpo educado: pedagogias da sexualidade (org.). 3. ed. Belo Horizonte: Autêntica, 2010.

LAURETIS, Teresa de. A tecnologia de gênero. In: HOLANDA, Heloisa Buarque de (Org.). Tendências e impasses: o feminismo como crítica cultural. Rio de Janeiro: Rocco, 1994. p. 206-242.

LE BRETON, David. Adeus ao corpo: Antropologia e sociedade. Campinas (SP): Papirus, 2003.

LOPES, Luiz Paulo Moita. Sexualidades em sala de aula: discurso, desejo e teoria queer. In: MOREIRA, Antônio Flávio; CANDAU, Vera Maria. Multiculturalismo: diferenças culturais e práticas pedagógicas. 4. ed. Petrópolis (RJ): Vozes, 2010.

LOURO, Guacira Lopes. Gênero, sexualidade e educação: uma perspectiva pós-estruturalista. 11. ed. Petrópolis (RJ): Vozes, 2010a.

LOURO, Guacira Lopes. Pedagogias de sexualidade. In: (org.). 0 corpo educado: pedagogias da sexualidade 3. ed. Belo Horizonte: Autêntica, 2010b. 
MORENO, Montserrat. Como se ensina e ser menina: o sexismo na escola. São Paulo: Moderna; Campinas (SP): UNICAMP, 1999.

PACHECO, Ana Claúdia Lemos. Discurso, gênero e sexualidade: questões contemporâneas. Revista Saberes em Perspectiva, v. 2, no 2, pp. 109-120, Jan./ Abr, 2012.

PARO, Vitor. Educação como exercício do poder: crítica ao senso comum em educação. 2. ed. São Paulo: Cortez, 2010.

PERROT, Michelle. As mulheres ou os silêncios da história. Bauru/SP: EDUSC, 2005.

SCOTT, Joan. The evidence of experience. Critical Inquiry, n. 17, p. 773-779, 1991.

SOFFER, Olga; ADOVASIO, J. M.; PAGE, Jake. 0 sexo invisível: o verdadeiro papel das mulheres na Pré-História. Rio de Janeiro: Record, 2009.

THOMPSON, E. P. A miséria da teoria ou um planetário de erros. Rio de Janeiro: Zahar, 1981.

XAVIER FILHA, Constantina. Representações de corpo masculino e feminino em pesquisa com crianças. Revista FACED, n.19, p.75-89, jan./jun. 2011.

Recebido em 14.09.2013

Aprovado em 23.11.2013 